\title{
BMJ Open How can the uptake of preventive behaviour during the COVID-19 outbreak be improved? An online survey of 4827 Chinese residents
}

Yimeng Mao, Hao Chen, Yi Wang, Suhong Chen, Junling Gao, Junming Dai, Yingnan Jia (1) , Qianyi Xiao (D) , Pinpin Zheng, Hua Fu (D)

To cite: Mao Y, Chen $\mathrm{H}$, Wang Y, et al. How can the uptake of preventive behaviour during the COVID-19 outbreak be improved? An online survey of 4827 Chinese residents. BMJ Open 2021;11:e042954. doi:10.1136/ bmjopen-2020-042954

- Prepublication history for this paper is available online. To view these files, please visit the journal online (http://dx.doi org/10.1136/bmjopen-2020042954).

Received 21 July 2020 Revised 20 November 2020 Accepted 07 January 2021
Check for updates

(C) Author(s) (or their employer(s)) 2021. Re-use permitted under CC BY-NC. No commercial re-use. See rights and permissions. Published by BMJ.

School of Public Health, Institute of Health Communication, Key Lab of Public Health Safety of Ministry of Education, Fudan University, Shanghai, China

\section{Correspondence to}

Dr Qianyi Xiao;

xiaoqianyi@fudan.edu.cn and

Dr Pinpin Zheng;

zpinpin@shmu.edu.cn

\section{ABSTRACT}

Objectives The aims of this study were to assess the uptake of preventive behaviour during the COVID-19 outbreak and to investigate the factors influencing the uptake of preventive behaviour based on the theory of planned behaviour (TPB ) .

Design, setting and participants A cross-sectional online survey was conducted among Chinese residents aged $\geq 18$ years and 4827 participants from 31 provinces and autonomous regions were included in the current study. Uptake of preventive behaviour, attitude towards the spread of COVID-19 and preventive behaviour, subjective norms, perceived behavioural control, demographic characteristics and the information attention and processing mode were measured. Multivariate logistic regressions were used to identify associations between the potential influencing factors and uptake of preventive behaviour.

Results There were 2393 (52.8\%) respondents reported high uptake of preventive behaviour. Multivariate analyses demonstrated that attitude towards the behaviour, subjective norms and perceived behavioural control were significantly correlated with uptake of preventive behaviour, and perceived behavioural control was the strongest influencing factor $(\mathrm{OR}=4.09,95 \% \mathrm{Cl} 3.57$ to 4.69). Furthermore, systematic information processing mode was positively associated with high uptake of preventive behaviour compared with heuristic information processing mode $(\mathrm{OR}=2.16,95 \% \mathrm{Cl} 1.67$ to 2.81$)$.

Conclusions These findings are helpful for developing education and interventions to promote high uptake of preventive behaviour and enhance public health outcomes during pandemic.

\section{INTRODUCTION}

The WHO declared the COVID-19 outbreak a pandemic on 11 March 2020. By 10 June 2020, 7805148 confirmed cases of COVID-19 and 431192 deaths had been reported globally. ${ }^{1}$ In the absence of a vaccine to prevent COVID-19, the best way to prevent illness is to avoid being exposed to the virus. Early in the outbreak of COVID-19, the Chinese government, the Chinese Center for Disease

\section{Strengths and limitations of this study}

We referred to the item in the theory of planned behaviour (TPB) to choose the potentially influencing factors of the uptake of preventive behaviour and explore the predictor of uptake of preventive behaviour during COVID-19.

- Information attention and systematic information processing mode regarding pandemic were helpful for promoting high uptake of preventive behaviour, which may provide references for epidemic control in other countries.

- Online survey was used for rapid assessment, which may lead to selection bias.

- The survey was completed in the relatively shorttime period, so the results may not reflect the longterm practice of preventive measures.

- The measurement accuracy heavily depends on respondents' ability or willingness to recall their behaviours, which may be underreported or overreported.

Control and Prevention (CDC), and local health departments implemented measures to control the transmission of COVID-19, including isolation and quarantine, contact tracing of persons with COVID-19 and community containment. These aggressive measures appear to be successful in reducing the number of deaths and hospitalisations ${ }^{23}$ and could keep the disease at a level that does not exceed the capacity of the healthcare system. ${ }^{4}$

Additionally, measures related to improved personal hygiene were widely publicised in the media as a way to prevent infection. An improved understanding of the drivers of refusal to engage in nonpharmaceutical interventions may help tailor messaging and increase the chances of eliciting behavioural change. ${ }^{5}$ Several studies have reported that transmission may occur early in the course of infection ${ }^{6}$ and that persons who show no 
signs or symptoms of respiratory infection nevertheless shed SARS-CoV-2, the virus that causes COVID-19. ${ }^{23}$ In addition, the communicable period, defined as the interval from the first day of positive nucleic acid tests to the first day of continuous negative tests, can be up to 3 weeks, and patients in this communicable period could develop severe illness. ${ }^{7}$ Under such circumstances, several institutions, including the WHO, the Chinese CDC and the US CDC, recommend that the general public take preventive actions to prevent the spread of respiratory diseases, such as avoiding travel to highrisk areas and contact with individuals who are symptomatic, washing hands frequently with soap and water and wearing a mask if going out. ${ }^{8-10}$ In China, considering that China's population density is much higher than that in most other countries, which increases the likelihood of virus transmission, the Chinese CDC and National Health Commission of the People's Republic of China additionally recommended wearing masks when out in public, decreasing communication and avoiding nonessential excursions. ${ }^{11}$ All these findings and official recommendations indicate that individual behaviour is essential in controlling the pandemic. Hence, it is important to investigate the factors influencing people's uptake of preventive behaviour to minimise the spread of COVID-19. The theory of planned behaviour (TPB), which has been widely applied to explain many types of behaviours, ${ }^{12} 13$ suggests that one's intention is the most important predictor leading to behaviour and is determined by three direct factors: attitude towards the behaviour (a favourable or unfavourable evaluation of the particular behaviour), subjective norms (perceived social pressure to perform or not perform the behaviour) and perceived behavioural control (the perception of self-efficacy with respect to the ability to perform the behaviour). ${ }^{121415}$ Previous studies based on the ТРВ have demonstrated that attitude towards the behaviour, subjective norms and perceived behavioural control have a significant positive influence on self-isolation during a pandemic emergency. ${ }^{16}$ Furthermore, the TPB model was reported to explain $51.7 \%(\mathrm{p}<.001)$ of the variance in A/HINI vaccine intentions, ${ }^{17}$ and the extended TPB could predict $60 \%$ of adults' intention to receive the swine flu vaccine. ${ }^{18}$ In addition, several other factors may affect the uptake of preventive behaviour. The information processing mode can interact with social media to influence people's perception formation ${ }^{19}$ and then affect behaviour; sociodemographic characteristics such as gender ${ }^{20-22}$ and education ${ }^{23}$ were also reported to affect attitudes and behaviours related to pandemics.

To date, few studies in the health context have investigated the factors influencing uptake of preventive behaviour during the COVID-19 outbreak. Considering the global spread of COVID-19, we aim to investigate the factors related to uptake of preventive behaviour referring to the items in TPB to identify ways to promote the uptake of preventive behaviour among the public and provide a reference for epidemic control in other countries.
METHOD

\section{Design and participants}

This cross-sectional online survey was conducted through the Wenjuanxing platform (https://www.wjx.cn/app/ survey.aspx) from 31 January to 2 February 2020. The survey took approximately $10 \mathrm{~min}$ to complete, and an item with required answer was established to avoid the return of invalid questionnaires. Chinese residents aged $\geq 18$ years were invited through social media to participate in the survey. Since this online survey was disseminated via website and WeChat, the number of people who were reached could not be acquired. In total, 5851 surveys were returned. After information sorting and cleaning, we removed the invalid questionnaires, including those spent less than $5 \mathrm{~min}$ completing the questionnaires, which are based on the entire large questionnaire included 97 items designed by our research team, and those failed to answer the quality control questions. Finally, 4827 participants from 31 provinces and autonomous regions were included in the current study.

\section{Patient and public involvement statement}

Some participants were invited to help design the questionnaires and attend the pilot survey separately, but they were not involved in the recruitment, conduct, reporting or dissemination plans. The results of the survey have already been disseminated to all participants via website and WeChat, especially behavioural advice for prevention of COVID-19.

\section{Selection of factors related to uptake of preventive behaviour and measurements}

Uptake of preventive behaviour: as a dependent variable, the degree of uptake of preventive behaviour was included in the study to measure if people uptake the personal precaution against COVID-19. Scales ranging from $1=$ I strongly disagree to $5=I$ strongly agree measured people's recent uptake of preventive measures captured in these four statements: (1) 'since the outbreak of COVID-19, I have been wearing a mask in public', (2) 'since the outbreak of COVID-19, I have washed my hands more frequently and thoroughly with soap and water', (3) 'since the outbreak of COVID-19, I have avoided nonessential conversation and personal contact with others' and (4) 'since the outbreak of COVID-19, I have avoided nonessential going out or taking public transportation'. Because all the four items were referred to the guidelines published by China CDC and WHO and were all important and basic individual behaviours to prevent COVID-19, therefore, in this study, only participants who chose 5 (strongly agree) for all four questions were defined as having high uptake of preventive behaviour.

We explored the factors related to uptake of preventive behaviour referring to the items in TPB. In addition, the resources and opportunities available to a person, such as the availability of masks, to some extent dictate the likelihood of intended and actual behaviour. ${ }^{24}$ Moreover, we added other potential influencing factors. As shown in 


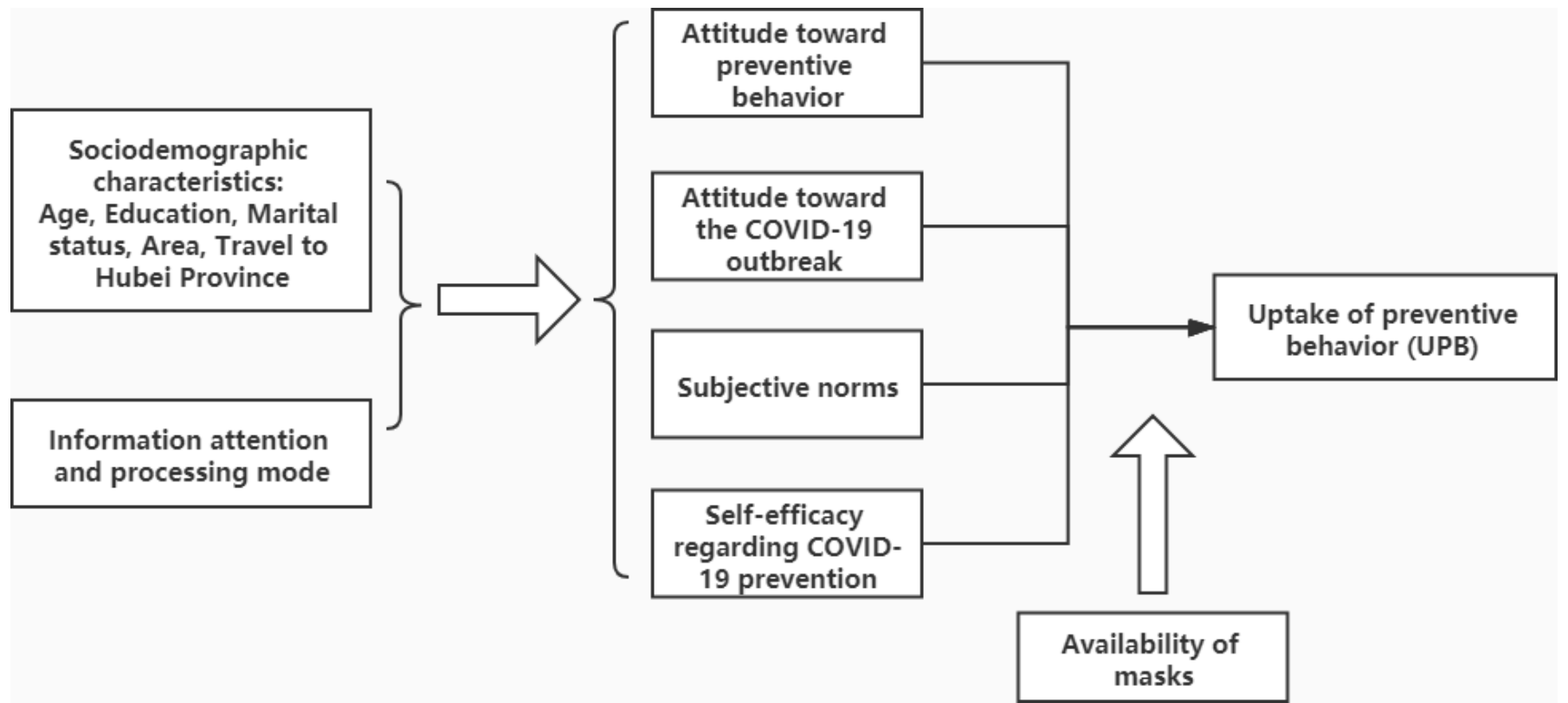

Figure 1 Application of the theory of planned behaviour to investigate predictors of uptake of protective behaviours in the context of COVID-19 pandemic.

figure 1, we added 'attitude towards COVID-19 outbreak' to the attitude towards the behaviour section because it could directly influence the attitude towards preventive behaviour. ${ }^{25}{ }^{26}$ Subjective norms were measured using the perception about the public preventive action, which directly bring the social pressure. Three questions related to self-efficacy were used to assess perceived behavioural control. $^{27}$

Uptake of preventive behaviour, attitude towards the behaviour, subjective norms, perceived behavioural control and the information attention and processing mode were measured by questionnaires. The detailed information of survey questions, variable description and processing were shown in table 1 .

\section{Statistical analyses}

The $\mathrm{X}^{2}$ test was applied to determine the prevalence of the uptake of preventive behaviour by the categorical variables, including demographic characteristics, attitude towards the behaviour, subjective norms, perceived behavioural control, degree of attention to COVID-19 and the information processing mode. The underlying structure of the items and their factor loadings were identified by using the exploratory factor analysis (EFA); the extraction was made using the principal components and the rotation using the Varimax method. Multivariate logistic regression analyses were applied to assess the association between the potential influencing factors and the uptake of preventive behaviour after controlling for related characteristic covariates. Adjusted ORs and their 95\% CIs were used to quantify the effects. The sensitivity, specificity and the area under the receiver operating characteristic (ROC) curve were calculated to evaluate the logistic regression model. SPSS software V.22.0 (SPSS, Chicago, Illinois, USA) was used to carry out all analyses.
All tests were two sided, and $\mathrm{p}<0.05$ was considered statistically significant.

\section{RESULTS}

\section{Descriptive statistics}

Among the 5851 questionnaires returned, 4827 $(82.5 \%)$ were valid, reflecting a completion rate of $83.27 \%$. We additionally excluded 294 participants who could not buy masks. Ultimately, 4533 participants were included in the analysis. Table 2 provides descriptive statistics for the characteristics of the respondents. Overall, the mean age of the respondents was $32.45 \pm 9.971$ years (range $18-85, I Q R=13$ ), and almost half of the respondents were between the ages of 21 and 30 . Of the participants, $68.1 \%$ were women. The majority of the respondents $(62.1 \%)$ had a bachelor's degree or a college education. More than half of respondents $(55.0 \%)$ were married. Only $5.3 \%$ were medical staff and $2.7 \%$ had a history of travel to Hubei Province (the high risk areas of COVID-19 outbreak). Approximately $82.0 \%$ lived in urban areas and $18.0 \%$ reported that someone in their community was suspected or confirmed to have COVID-19.

Regarding preventive behaviour, $75.1 \%$ of the respondents reported that they wore masks when going outside, $66.1 \%$ washed their hands frequently, $66.0 \%$ avoiding talking to or touching others and $73.0 \%$ avoided unnecessary use of public transportation. Overall, 52.8\% of participants reported high uptake of preventive behaviour. As shown in table 2, the proportion of high uptake of preventive behaviour among men $(51.0 \%)$ was lower than that among women $(53.6 \%)$. The uptake of preventive behaviour 


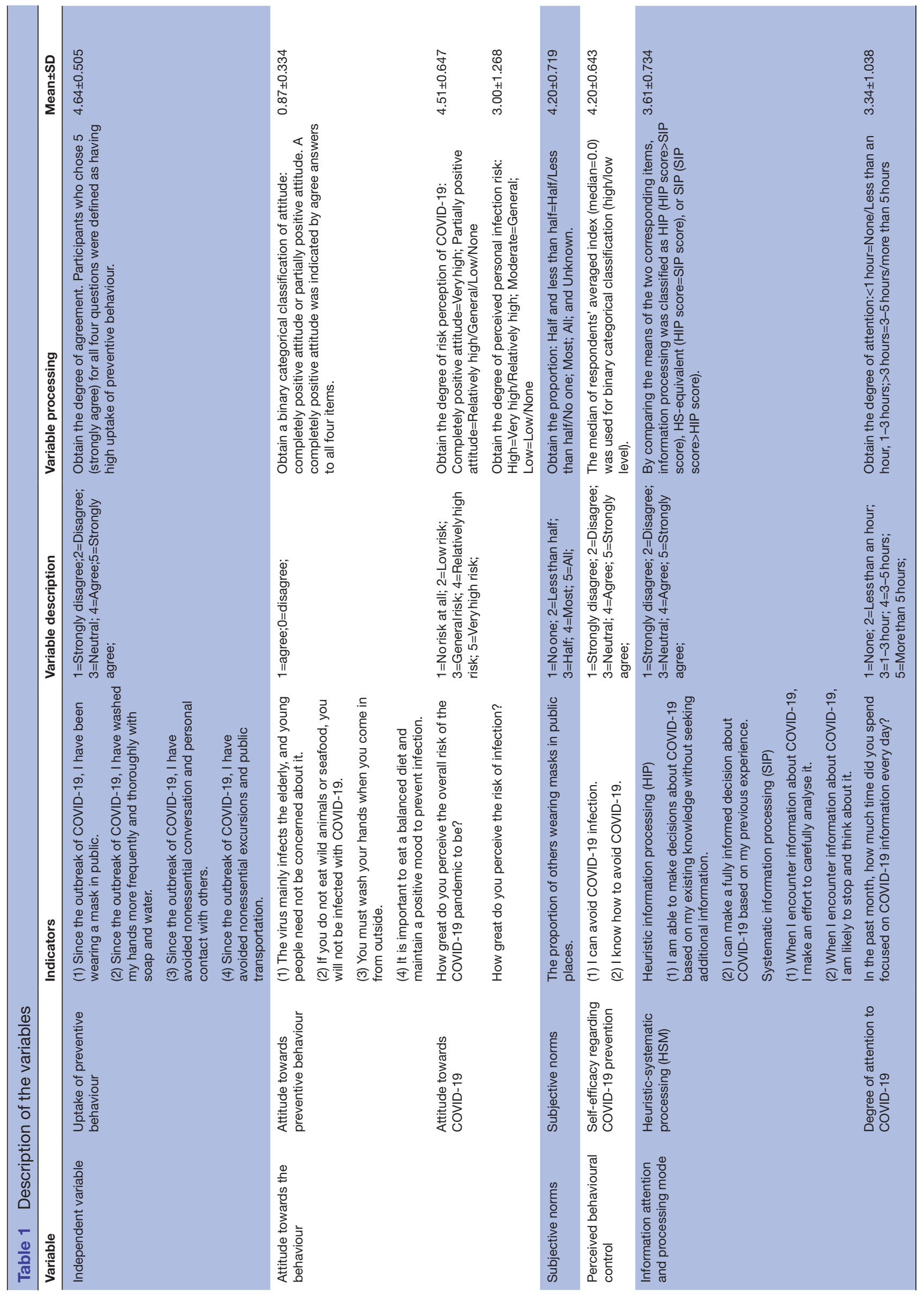


Table 2 Participants' characteristics and uptake of preventive behaviour

\begin{tabular}{|c|c|c|c|c|c|}
\hline & Total N (\%) & $\begin{array}{l}\text { Low uptake of preventive } \\
\text { behaviour } \mathrm{N}(\%)\end{array}$ & $\begin{array}{l}\text { High uptake of preventive } \\
\text { behaviour } \mathrm{N}(\%)\end{array}$ & $\chi^{2}$ & $\mathbf{P}$ \\
\hline Gender & & & & 2.752 & 0.097 \\
\hline Male & $1444(31.9)$ & $708(49.0)$ & $736(51.0)$ & & \\
\hline Female & $3089(68.1)$ & $1433(46.4)$ & $1656(53.6)$ & & \\
\hline Age (years) & & & & 30.255 & $<0.001$ \\
\hline$<20$ & $234(5.2)$ & $140(59.8)$ & $94(40.2)$ & & \\
\hline $21-30$ & $2145(47.3)$ & $1058(49.3)$ & $1087(50.7)$ & & \\
\hline $31-40$ & $1236(27.3)$ & $538(43.5)$ & $698(56.5)$ & & \\
\hline $41-50$ & 705 (15.6) & $304(43.1)$ & 401 (56.9) & & \\
\hline$>51$ & $213(4.7)$ & $101(47.4)$ & $112(52.6)$ & & \\
\hline Education & & & & 31.925 & $<0.001$ \\
\hline Middle school & $240(5.3)$ & $113(47.1)$ & 127 (52.9) & & \\
\hline High School & $742(16.4)$ & $301(40.6)$ & $441(59.4)$ & & \\
\hline College & $2817(62.1)$ & $1322(46.9)$ & $1495(53.1)$ & & \\
\hline Master's degree & $734(16.2)$ & 405 (55.2) & $329(44.8)$ & & \\
\hline Marital status & & & & 55.88 & $<0.001$ \\
\hline Married & $2492(55.0)$ & $1052(42.2)$ & $1440(57.8)$ & & \\
\hline Not married & $2041(45.0)$ & $1089(53.4)$ & $952(46.6)$ & & \\
\hline Occupation & & & & 0.014 & 0.906 \\
\hline Healthcare worker & $239(5.3)$ & $112(46.9)$ & $127(53.1)$ & & \\
\hline Other & $4294(94.7)$ & $2029(47.3)$ & $2265(52.7)$ & & \\
\hline Province & & & & 0.982 & 0.322 \\
\hline Hubei & $124(2.7)$ & $64(51.6)$ & $60(48.4)$ & & \\
\hline Other & $4409(97.3)$ & $2077(47.1)$ & $2332(52.9)$ & & \\
\hline Area & & & & 10.87 & 0.001 \\
\hline Urban & 3719 (82.0) & $1714(46.1)$ & 2005 (53.9) & & \\
\hline Rural & $814(18.0)$ & 427 (52.5) & $387(47.5)$ & & \\
\hline Community COVID-19 epidem & & & & 4.844 & 0.184 \\
\hline No COVID-19 cases & $3488(76.9)$ & $1626(46.6)$ & $1862(53.4)$ & & \\
\hline Under medical observation & $376(8.3)$ & $191(50.8)$ & $185(49.2)$ & & \\
\hline Suspected case & $242(5.3)$ & $126(52.1)$ & $116(57.9)$ & & \\
\hline Confirmed case & $427(9.4)$ & $198(46.4)$ & $229(53.6)$ & & \\
\hline Travel to Hubei & & & & 7.861 & 0.005 \\
\hline No & $4176(92.1)$ & $1947(46.6)$ & $2229(53.4)$ & & \\
\hline Yes & 357 (7.9) & $194(54.3)$ & $163(45.7)$ & & \\
\hline \multicolumn{6}{|l|}{ Self-rate health } \\
\hline Poor & $254(11.9)$ & $208(8.7)$ & $462(10.2)$ & 12.387 & $<0.001$ \\
\hline Good & 1887 (88.1) & 2184 (91.3) & 4071 (89.8) & & \\
\hline
\end{tabular}

was also influenced by age, with those 31-50 years old accounting for the highest proportion of high uptake of preventive behaviour and those younger than 20 accounting for the lowest proportion of high uptake of preventive behaviour. Education was also an influencing factor, with the highest proportion of high uptake of preventive behaviour observed among respondents with a high school education and the lowest proportion among respondents with a master's degree. Respondents from urban areas reported a significantly higher proportion of high uptake of preventive behaviour than those from rural areas $(53.9 \%$ vs $47.5 \%)$. Respondents who had a history of travel to Hubei Province $(53.4 \%)$ reported a higher proportion of high uptake of preventive behaviour than others $(45.7 \%)$. 
Table 3 The results of factor analysis referring to the items in TPB

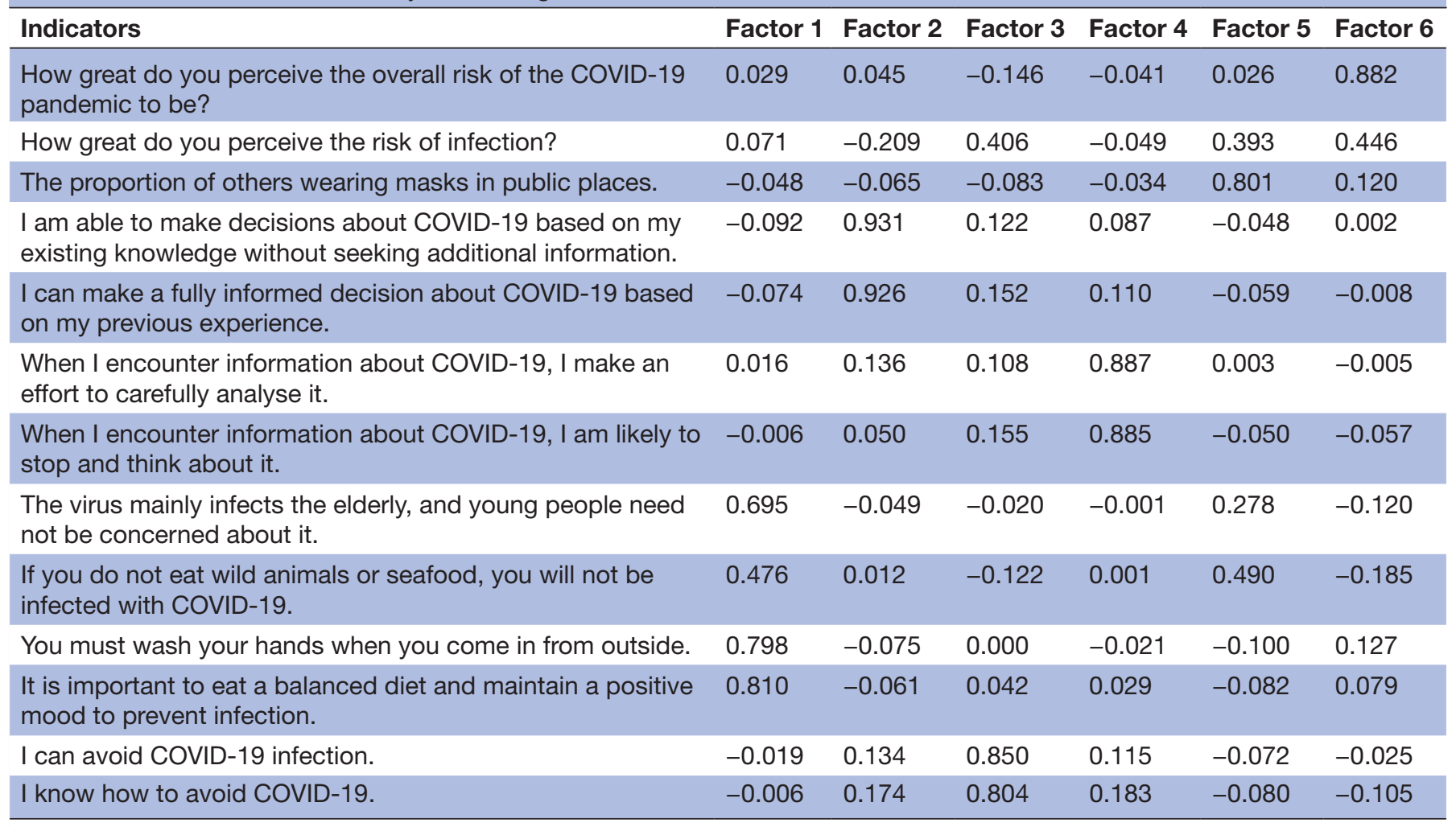

TPB, theory of planned behaviour.

\section{Association of the uptake of preventive behaviour with influencing factors}

Considering that potential influencing factors of uptake of preventive behaviour were designed referring to the items in TPB, EFA was first performed to examine the underlying structure of the items and their factor loadings to support and strengthen the following association analysis of the uptake of preventive behaviour with influencing factors. As shown in table 3, the EFA result was in accordance with items been grouped into constructs in table 1 . The proportion of the variance explained by the retained factors was $72.2 \%$ and the Cronbach's alpha of all items is 0.6.

As shown in table 4, multivariable logistic regression analysis was used to test the influencing factors associated with the uptake of preventive behaviour. The fully fitted model had an ROC value of 0.727 while put in all the factors of the regression. For attitude towards the behaviour, compared with those with partially positive attitudes, respondents with completely positive attitudes towards preventive behaviour ( $\mathrm{OR}=1.42,95 \% \mathrm{CI} 1.16$ to 1.73$)$ or paid attention towards the risk of COVID-19 (OR=1.73, 95\% CI 1.52 to 1.97) had increased adjusted odds of high uptake of preventive behaviour. Regarding subjective norms, perceptions of a higher proportion of public precaution increased the adjusted odds of high uptake of preventive behaviour (most vs half and less than half: OR=1.52, 95\% CI 1.15 to 2.00, all vs half and less than half: $\mathrm{OR}=1.67,95 \%$ CI 1.24 to 2.25, unknown vs half and less than half: $\mathrm{OR}=1.62,95 \% \mathrm{CI}$
1.09 to 2.42 , respectively). Perceived behavioural control was the strongest influencing factor of uptake of preventive behaviour. Respondents with high self-efficacy in preventing COVID-19 were 4.09 times more likely to have a high uptake of preventive behaviour than those with low self-efficacy ( $\mathrm{OR}=4.09,95 \%$ CI 3.57 to 4.69$)$. Furthermore, there are also several other influencing factors of uptake of preventive behaviour. Respondents who engaged more in systematic information processing (SIP) mode were more likely to have high uptake of preventive behaviour than those engaged more in Heuristic information processing (HIP) mode and Heuristic-systematic-equivalent information processing mode (SIP vs HIP: $\mathrm{OR}=2.16,95 \%$ CI 1.67 to 2.81, HS-equivalent vs HIP: OR=1.78, $95 \%$ CI 1.34 to 2.35). Increased attention to COVID-19 was significantly associated with increased adjusted odds of high uptake of preventive behaviour ( $1-3$ hours vs $<1$ hour: $\mathrm{OR}=1.19$, $95 \%$ CI 1.01 to 1.41 and $>3$ hours vs $<1$ hour: $\mathrm{OR}=1.39$, $95 \%$ CI 1.18 to 1.65$)$. Additionally, married and urban respondents had higher uptake of preventive behaviour than those who were not married (OR=1.25, 95\% CI 1.05 to 1.49$)$.

We also compared the characteristics of the respondents reporting that they could obtain masks and those reporting that they could not (table 5). The results indicated that respondents who were men $(\mathrm{OR}=1.39,95 \% \mathrm{CI}$ 1.09 to 1.78 ), not married ( $\mathrm{OR}=1.90,95 \% \mathrm{CI} 1.49$ to 2.42 ) or from a rural area $(\mathrm{OR}=2.11,95 \% \mathrm{CI} 1.64$ to 2.73$)$ were more likely to report that masks were not available. 
Table 4 Logistic regression of uptake of preventive behaviour

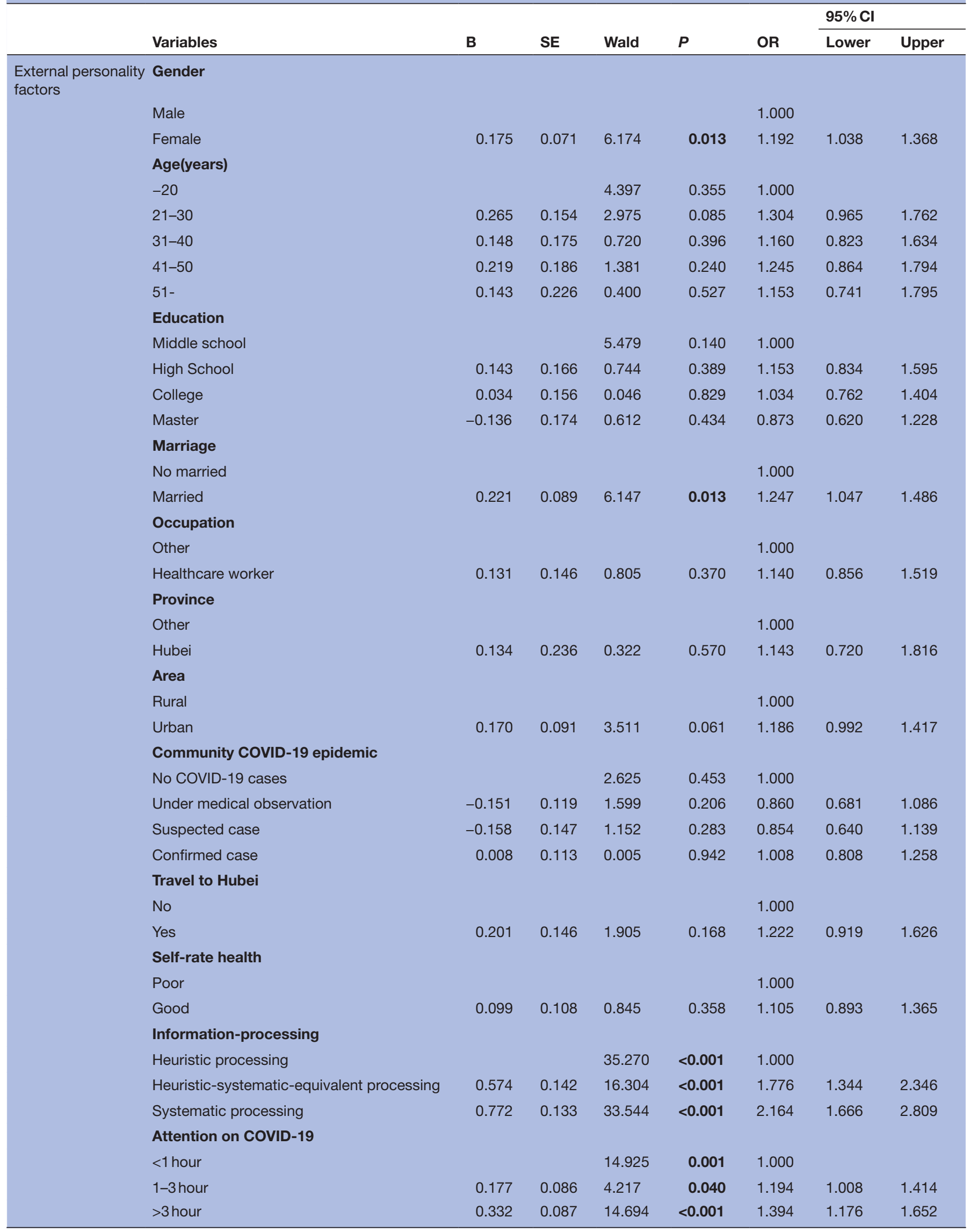


Table 4 Continued

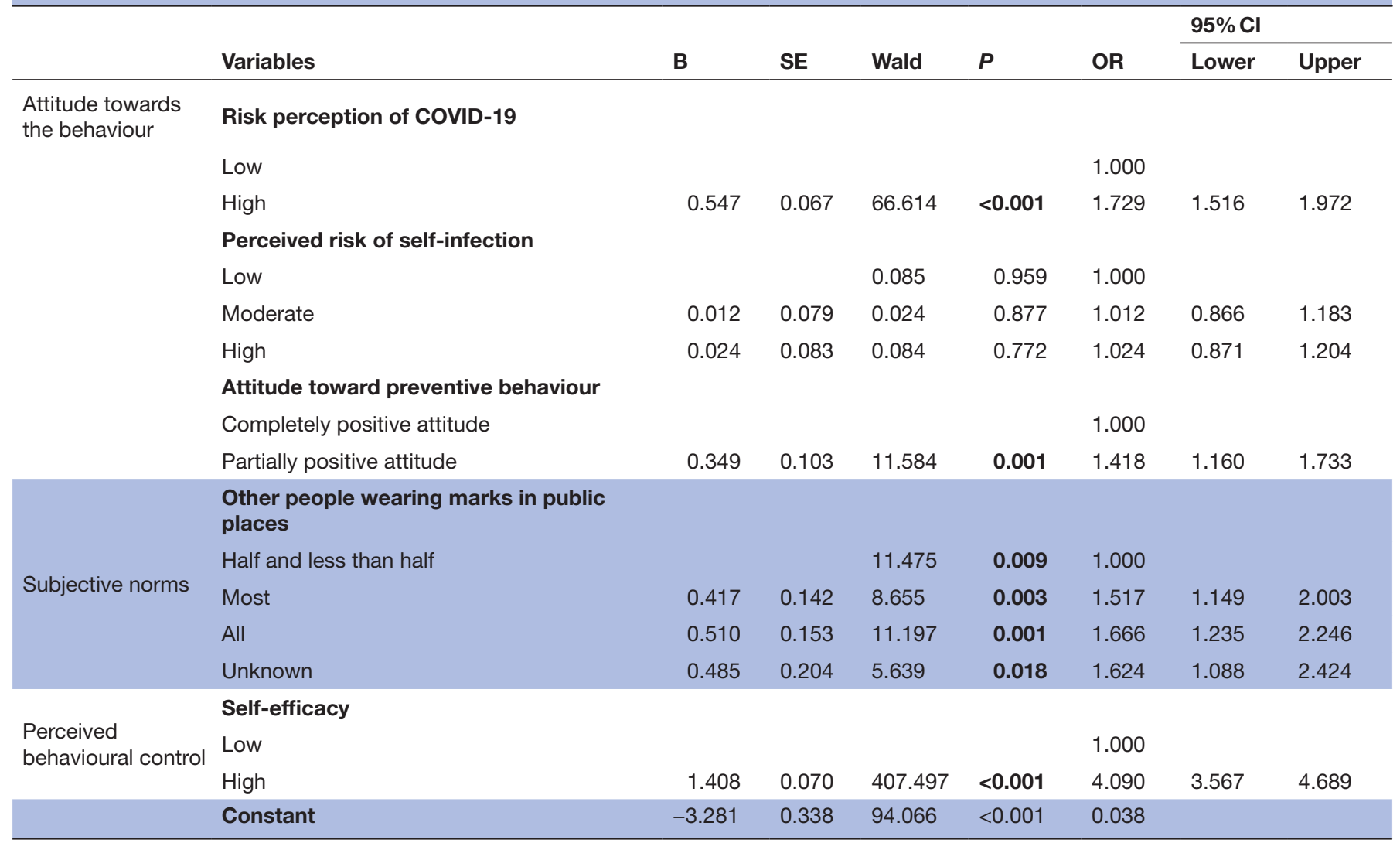

All the variables shown in table 4 included in a single model.

\section{DISCUSSION}

In the present study, we demonstrate that $52.8 \%$ of participants reported high uptake of preventive behaviour, with full compliance with wearing masks in public, frequent hand washing, avoidance of talking to or touching others and avoidance of unnecessary public transportation use. We explored the potential factors influencing the uptake of preventive behaviour during a pandemic referring to the items in TPB. The results show that attitude towards the behaviour, subjective norms and perceived behavioural control have significant influences on uptake of preventive behaviour. Information processing mode, attention to the pandemic and several sociodemographic characteristics also influenced high uptake of preventive behaviour.

The results showed that attitude towards the behaviour, subjective norms and perceived behavioural control have significant positive influences on the uptake of preventive behaviour in the context of COVID-19, which was consistent with a previous study that reported the positive influence of attitude towards the behaviour, subjective norms and perceived behavioural control on self-isolation during the pandemic. ${ }^{14}$ Of these three considered factors, perceived behavioural control (self-efficacy with respect to preventing COVID-19) was the strongest predictor. Respondents with high self-efficacy regarding preventing COVID-19 were 3.6 times more likely to have high uptake of preventive behaviour than those with low self-efficacy. This result supports previous studies indicating that selfefficacy will result in protection motivation leading to changes in attitudes, perceptions or behaviours. ${ }^{28}$ For attitude towards the behaviour, compared with a partially positive attitude, a completely positive attitude towards preventive behaviour or paid attention towards the risk of COVID-19 was significantly associated with high uptake of preventive behaviour; however, the degree of agreement with the likelihood of self-infection was not associated with high uptake of preventive behaviour in a multivariable analysis. Consistent with our findings, Kim also reported that the perceived likelihood of getting sick (cognitive element) was not strongly associated with preventive behaviours, whereas perceived concern (emotional element) was significantly associated with precautionary and preparatory behaviours. ${ }^{29}$ One possible reason is that the population is generally susceptible due to the highly contagious nature of the virus ${ }^{30}$; therefore, people's judgements of the severity of the pandemic better reflect their awareness and precautions.

It is worth noting that the information processing mode was a pivotal factor influencing the uptake of preventive behaviour during the COVID-19 outbreak. Respondents who engaged more in SIP were two times as likely to intend to take a high level of preventive behaviour against COVID-19 than those who engaged in HIP. SIP 
Table 5 Characteristics of respondents reporting the availability or unavailability of masks

Total $(n=4649)$ Masks are available $(n=4533)$ Masks are not available $(n=294) \chi^{2} \quad$ P

\begin{tabular}{|c|c|c|c|c|c|}
\hline \multicolumn{4}{|l|}{ Gender } & \multirow[t]{2}{*}{7.292} & \multirow[t]{2}{*}{0.007} \\
\hline Male & 1560 (32.3) & 1444 (92.6) & $116(7.4)$ & & \\
\hline Female & 3267 (67.7) & 3089 (94.6) & $178(5.4)$ & & \\
\hline$<20$ & $256(5.3)$ & 234 (91.4) & $22(8.6)$ & & \\
\hline $21-30$ & 2312 (47.9) & 2145 (92.8) & $167(7.2)$ & & \\
\hline $41-50$ & 749 (15.5) & 705 (94.1) & $44(5.9)$ & & \\
\hline$>51$ & $222(4.6)$ & 213 (95.9) & $9(4.1)$ & & \\
\hline \multicolumn{4}{|l|}{ Education } & 1.832 & 0.608 \\
\hline Middle school & $257(5.3)$ & $240(93.4)$ & $17(6.6)$ & & \\
\hline High School & $782(16.2)$ & 742 (94.9) & $40(5.1)$ & & \\
\hline \multicolumn{4}{|l|}{ Marital status } & 27.955 & $<0.001$ \\
\hline Married & 2607 (54.0) & 2492 (95.5) & $115(4.4)$ & & \\
\hline Not married & $2220(46.0)$ & 2041 (91.9) & $179(8.1)$ & & \\
\hline \multicolumn{4}{|l|}{ Occupation } & 0.794 & 0.373 \\
\hline Healthcare worker & $251(5.2)$ & 239 (95.2) & $12(4.8)$ & & \\
\hline Other & 4576 (94.5) & 4294 (93.8) & $282(6.2)$ & & \\
\hline \multicolumn{4}{|l|}{ Province } & 0.508 & 0.476 \\
\hline Hubei & $130(2.7)$ & $124(95.4)$ & $6(4.6)$ & & \\
\hline Other & 4697 (97.3) & 4409 (93.9) & $288(6.1)$ & & \\
\hline Suspected case & $262(5.43)$ & $242(92.4)$ & $20(7.6)$ & & \\
\hline Confirmed case & $454(9.41)$ & $427(94.1)$ & $27(5.9)$ & & \\
\hline
\end{tabular}

requires greater attention to acquiring information, ${ }^{31}$ so people engaged more in SIP will have greater risk awareness due to the evaluation of information and then uptake of preventive actions; however, this result should be interpreted in a specific context or situation, such as the COVID-19 pandemic, as people were unfamiliar and uninformed regarding the infectious disease. As Trumbo mentioned, the notion that only rational and systematic judgement can lead to suitable actions, avoidance of inadequate actions or unnecessary overreactions to risk needs to be re-examined. ${ }^{32}$ Additionally, information processing is an important component of health literacy, which can be understood as the capacity of individuals to obtain, process, and understand basic health information to make decisions to maintain health and improve quality of life. ${ }^{33}$ Hence, it may be an effective way to improve the health literacy and in turn uptake of preventive behaviour regarding the pandemic through educating the public to evaluate and analyse information (SIP mode) of pandemic.

The sociodemographic characteristic factors should also be given more attention. Our findings suggested that people living in rural areas have a lower proportion of high uptake of preventive behaviour than those living in urban areas, which may be due to poorer health literacy related to infectious diseases in rural areas than in urban areas. $^{34}$ Low literacy relates to less knowledge about health, which leads to decreased adherence to positive health behaviours. ${ }^{3536}$ Furthermore, marital status is an important social factor associated with human health and 
longevity. ${ }^{37-40}$ The marriage protection effect refers to the fact that married people have more advantages related to family support, including psychological support and health behaviour support. Our results support the protective role of marriage in the uptake of preventive behaviour during the pandemic. All these findings indicated that people living in rural areas and people who are not married should be given more attention in terms of health education and health promotion, and their social, psychological and physiological characteristics should be taken into account. In addition, the issue of mask availability among those who are men, over 31 years old, not married or from rural areas, should be taken into account because, in this survey, these people reported that masks were not available.

The results of this study should be considered in the light of the following limitations. First, an online survey was used for rapid assessment, which may have resulted in selection bias. For example, some older people with low education levels or serious chronic diseases may not be included in the survey, and more comprehensive investigations are needed. Second, this study relied on cross-sectional survey data to examine the relationships. Therefore, the results of the analyses should be interpreted with care because causal relationships between variables may exist. Third, the survey was completed in the relatively short time period, so the results may not reflect the long-term practice of preventive measures after the survey. Fourth, although self-report measures are very convenient and common in some fields of media research, ${ }^{41}$ the measurement accuracy heavily depends on respondents' ability or willingness to recall their behaviours, which may be underreported or overreported. Fifth, although our findings indicated the potential way of referring to the TPB theory to explore influencing factors of uptake of preventive behaviour in the early stage of COVID-19, the theoretical application is insufficient, which needs the further research with the modelling approach in the future study. Finally, our survey was based on social media, which may skew younger, educated and urban people, in turn may affect the generalisability.

\section{CONCLUSION}

Despite the cited limitations, our results are helpful for developing education and interventions to support health behaviours and enhance outcomes in the public during a pandemic emergency. Attitude towards the behaviour, subjective norms and perceived behavioural control has significant positive influences on the uptake of preventive behaviour during a pandemic, with perceived behavioural control (self-efficacy) playing the most important role. Therefore, developing education programmes focused on improving awareness of SIP and attention to the pandemic are helpful in promoting high uptake of preventive behaviour during pandemics.
Correction notice This article has been corrected since it was first published. The correcpoding author Pinpin Zheng email address has been corrected.

Acknowledgements We gratefully thank all participants for their cooperation.

Contributors PZ, JG, JD, YJ and HF designed the study and obtained the data. JG and JD organised. YM, YW, SC and HC performed the survey. YM and QX undertook the data analysis and interpretation supervised by PZ. QX and YM wrote the manuscript. PZ reviewed and commented on the manuscript. All authors read the final manuscript and agree with the text.

Funding This work was supported by the National Natural Science Foundation of China [71573047] and the grant from Shanghai Municipal Committee for Health and Family Planning (Award number: GWV-10.1-XK14)

Competing interests None declared.

Patient and public involvement Patients and/or the public were not involved in the design, or conduct, or reporting, or dissemination plans of this research.

Patient consent for publication Not required.

Ethics approval The Institutional Review Board of Fudan University, School of Public Health (IRB number 2020-01-0800), approved the study protocol.

Provenance and peer review Not commissioned; externally peer reviewed.

Data availability statement Data are available upon reasonable request. The data that support the findings of this study are available from School of Public Health, Fudan University but restrictions apply to the availability of these data, which were used under license for the current study, and so are not publicly available. Data are however available from the authors upon reasonable request and with permission of school of public health, Fudan University.

Open access This is an open access article distributed in accordance with the Creative Commons Attribution Non Commercial (CC BY-NC 4.0) license, which permits others to distribute, remix, adapt, build upon this work non-commercially, and license their derivative works on different terms, provided the original work is properly cited, appropriate credit is given, any changes made indicated, and the use is non-commercial. See: http://creativecommons.org/licenses/by-nc/4.0/.

ORCID iDs

Yingnan Jia http://orcid.org/0000-0001-9211-4061

Qianyi Xiao http://orcid.org/0000-0002-3349-302X

Hua Fu http://orcid.org/0000-0001-8649-1899

\section{REFERENCES}

1 WHO. Coronavirus(COVID-19) situation report, 2020. Available: https://who.sprinklr.com/

2 Hoehl S, Rabenau H, Berger A, Kortenbusch M, et al. Evidence of SARS-CoV-2 infection in returning travelers from Wuhan, China. $N$ Engl J Med 2020;382:1278-80.

3 Zou L, Ruan F, Huang M, et al. SARS-CoV-2 viral load in upper respiratory specimens of infected patients. N Engl J Med 2020;382:1177-9.

4 Aleta A, Martín-Corral D, Piontti APY, et al. Modeling the impact of social distancing, testing, contact tracing and household quarantine on second-wave scenarios of the COVID-19 epidemic. medRxiv 2020. doi:10.1101/2020.05.06.20092841. [Epub ahead of print: 18 May 2020].

5 Kantor BN, Kantor J. Non-pharmaceutical interventions for pandemic COVID-19: a cross-sectional investigation of US General public beliefs, attitudes, and actions. Front Med 2020;7:384.

6 Rothe C, Schunk M, Sothmann P, et al. Transmission of 2019-nCoV infection from an asymptomatic contact in Germany. N Engl J Med 2020;382:970-1.

$7 \mathrm{Hu}$ Z, Song C, Xu C, et al. Clinical characteristics of 24 asymptomatic infections with COVID-19 screened among close contacts in Nanjing, China. Sci China Life Sci 2020;63:1-6.

8 CDC. Chinses centers disease control and prevention, prevention of coronavirus: an authoritative tip from China CDC, 2020. Available: http://www.chinacdc.cn/jkzt/crb/zl/szkb_11803/jszl_2275/202001/ t20200125_211423.html

9 Centers for Disease Control and Prevention. 2019 novel coronavirus, 2020. Available: https://www.cdc.gov/coronavirus/2019-ncov/about/ transmission.html

10 WHO. Novel coronavirus (2019-nCoV) advice for the public, 2020. Available: https://www.who.int/emergencies/diseases/novelcoronavirus-2019/advice-for-public 
11 China NHCO. Health education manual for novel coronavirus infection pneumonia. Organ Behav Hum Dec 1991;50:179-211.

12 Ajzen I. The theory of planned behavior. Organ Behav Hum Decis Process 1991;50:179-211.

13 Armitage CJ, Conner M. Efficacy of the theory of planned behaviour: a meta-analytic review. Br J Soc Psychol 2001;40:471-99.

14 Connor MSP. Theory of planned behaviour and Health Behaviour. In Connor M, ed. In predicting health behaviour, 2 edition ed. Oxford: Oxford University Press, 2005: 170-222.

15 Bandura A. Self-Efficacy: toward a unifying theory of behavioral change. Psychol Rev 1977;84:191-215.

16 Zhang $X$, Wang F, Zhu C, et al. Willingness to Self-Isolate when facing a pandemic risk: model, empirical test, and policy recommendations. Int J Environ Res Public Health 2019;17. doi:10.3390/ijerph17010197. [Epub ahead of print: 2712 2019].

17 Agarwal V. A/H1N1 vaccine intentions in college students: an application of the theory of planned behavior. J Am Coll Health 2014;62:416-24.

18 Myers LB, Goodwin R. Determinants of adults' intention to vaccinate against pandemic swine flu. BMC Public Health 2011;11:15.

19 Lee E-J, Oh SY. Seek and you shall find? how need for orientation moderates knowledge gain from Twitter use. J Commun 2013;63:745-65.

20 DeLay P. Gender and monitoring the response to HIV / AIDS pandemic. Emerg Infect Dis 2004;10:1979-83.

21 Park J-H, Cheong H-K, Son D-Y, et al. Perceptions and behaviors related to hand hygiene for the prevention of $\mathrm{H} 1 \mathrm{~N} 1$ influenza transmission among Korean university students during the peak pandemic period. BMC Infect Dis 2010;10:222.

22 Ek S. Gender differences in health information behaviour: a Finnish population-based survey. Health Promot Int 2015;30:736-45.

23 Wong LP, Sam I-C. Public Sources of Information and Information Needs for Pandemic Influenza A(H1N1). J Community Health 2010;35:676-82.

24 Terry DJ, O'Leary JE. The theory of planned behaviour: the effects of perceived behavioural control and self-efficacy. Br J Soc Psychol 1995;34:199-220.

25 Fazio RH, Zanna MP. Direct experience and Attitude-Behavior consistency. Adv Exp Soc Psychol 1981;14:161-202.

26 La Torre G, Semyonov L, Mannocci A, et al. Knowledge, attitude, and behaviour of public health doctors towards pandemic influenza compared to the general population in Italy. Scand J Public Health 2012;40:69-75.
27 Choi D-H, Yoo W, Noh G-Y, et al. The impact of social media on risk perceptions during the MERS outbreak in South Korea. Comput Human Behav 2017;72:422-31.

28 Dorsey AM, Miller KI, Scherer CW. Communication, risk behavior, and perceptions of threat and efficacy: a test of a reciprocal model. Journal of Applied Communication Research 1999;27:377-95.

29 Kim Y, Zhong W, Jehn M, et al. Public risk perceptions and preventive behaviors during the $2009 \mathrm{H} 1 \mathrm{~N} 1$ influenza pandemic. Disaster Med Public Health Prep 2015;9:145-54.

30 Zhao S, Lin Q, Ran J, et al. Preliminary estimation of the basic reproduction number of novel coronavirus (2019-nCoV) in China, from 2019 to 2020: a data-driven analysis in the early phase of the outbreak. Int J Infect Dis 2020;92:214-7.

31 Eagly A, Chaiken S. The psychology of attitudes. Fort Worth, TX: HBJ Inc, 1993

32 Trumbo CW. Heuristic-systematic information processing and risk judgment. Risk Anal 1999;19:391-400.

33 Parker RM, Ratzan SC, Lurie N. Health literacy: a policy challenge for advancing high-quality health care. Health Aff 2003;22:147-53.

34 Wu S-sheng, Yang P, Li H-yue, Shuang-sheng YPLH WU, et al. [Analysis of status and influence factors of health literacy related to infectious diseases in residents of Beijing]. Beijing Da Xue Xue Bao Y Xue Ban 2012;44:607-11.

35 Guo Y, Logan HL, Dodd VJ, et al. Health literacy: a pathway to better oral health. Am J Public Health 2014;104:e85-91.

36 Fleary SA, Joseph P, Pappagianopoulos JE. Adolescent health literacy and health behaviors: a systematic review. J Adolesc 2018;62:116-27.

37 Goldman N, Hu Y. Excess mortality among the unmarried: a case study of Japan. Soc Sci Med 1993;36:533-46.

38 Shor E, Roelfs DJ, Bugyi P, et al. Meta-Analysis of marital dissolution and mortality: Reevaluating the intersection of gender and age. Soc Sci Med 2012;75:46-59.

39 Sorlie PD, Backlund E, Keller JB. Us mortality by economic, demographic, and social characteristics: the National longitudina mortality study. Am J Public Health 1995;85:949-56.

40 Davis MA, Murphy SP, Neuhaus JM, et al. Living arrangements affect dietary quality for U.S. adults aged 50 years and older: NHANES III 1988-1994. J Nutr 2000;130:2256-64.

41 de Vreese $\mathrm{CH}$, Neijens P. Measuring media exposure in a changing communications environment. Commun Methods Meas 2016;10:69-80. 